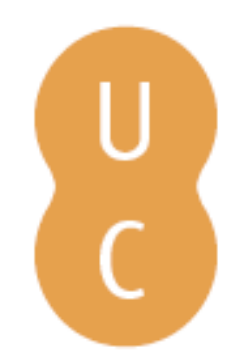

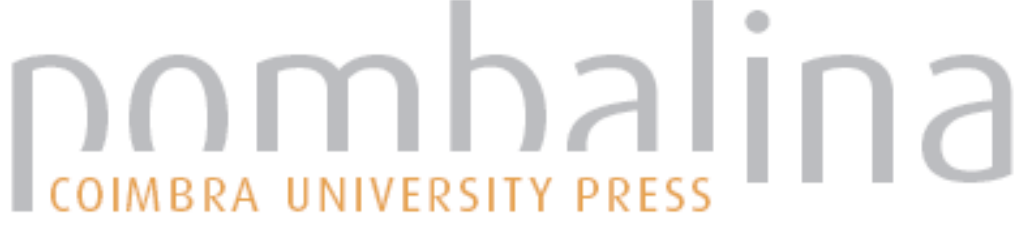

\section{Os estudos vicentinos}
Autor(es): $\quad$ Bernardes, José Augusto Cardoso
Publicado por: Imprensa da Universidade de Coimbra
URL persistente:
URI:http://hdl.handle.net/10316.2/47482
DOI:
DOI:https://doi.org/10.14195/978-989-26-1548-6_20

Accessed : $\quad$ 26-Apr-2023 10:11:28

A navegação consulta e descarregamento dos títulos inseridos nas Bibliotecas Digitais UC Digitalis, UC Pombalina e UC Impactum, pressupõem a aceitação plena e sem reservas dos Termos e Condições de Uso destas Bibliotecas Digitais, disponíveis em https://digitalis.uc.pt/pt-pt/termos.

Conforme exposto nos referidos Termos e Condições de Uso, o descarregamento de títulos de acesso restrito requer uma licença válida de autorização devendo o utilizador aceder ao(s) documento(s) a partir de um endereço de IP da instituição detentora da supramencionada licença.

Ao utilizador é apenas permitido o descarregamento para uso pessoal, pelo que o emprego do(s) título(s) descarregado(s) para outro fim, designadamente comercial, carece de autorização do respetivo autor ou editor da obra.

Na medida em que todas as obras da UC Digitalis se encontram protegidas pelo Código do Direito de Autor e Direitos Conexos e demais legislação aplicável, toda a cópia, parcial ou total, deste documento, nos casos em que é legalmente admitida, deverá conter ou fazer-se acompanhar por este aviso.

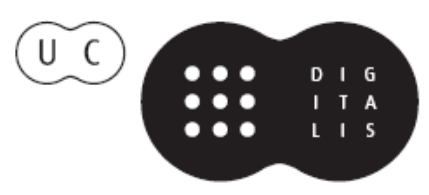



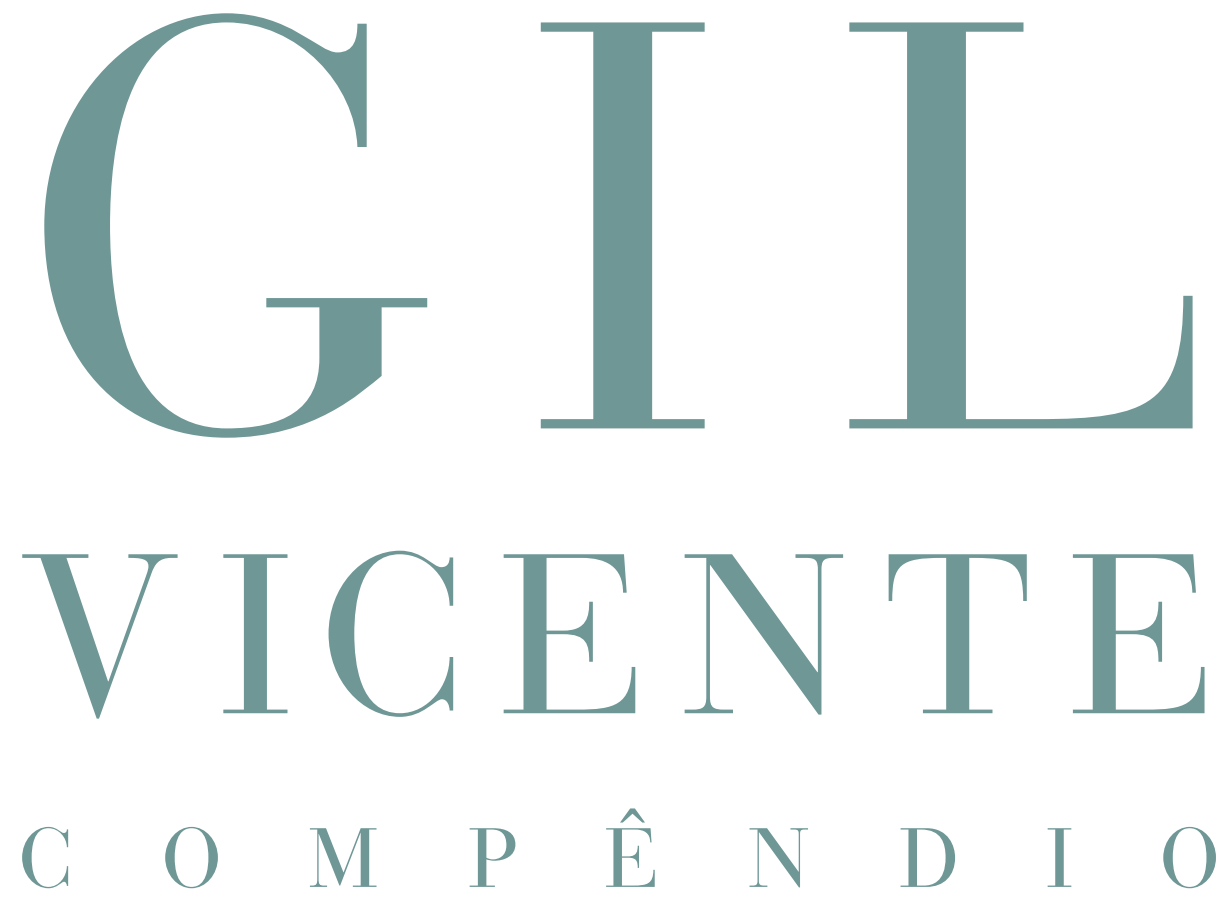

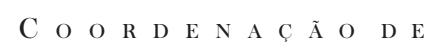

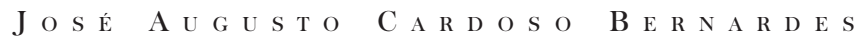

E J O S É C A M Õ E S

CoimbraCompanions

IVPRENSA DA UNIVERSIDADE DE COIMBRA

COIMBRA UNIVERSITY PRESS

IMPRENSA NACIONAL 


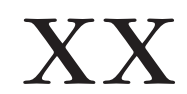

\section{Os estudos vicentinos}

José Augusto Cardoso Bernardes

Centro de literatura Portuguesa

UnIVERSIDADE DE COIMBRA 
(Página deixada propositadamente em branco) 
Se excetuarmos o invulgar estrelato que corresponde a Camões e a voga mais recente de Pessoa, nenhum escritor português inspirou tanto entusiasmo e atenção crítica como Gil Vicente. Conhecem-se bem os fatores (intrínsecos e extrínsecos) que explicam a fama dos dois primeiros. Já não é tão simples identificar os motivos que podem estar na base da fortuna crítica de Gil Vicente. Perguntemos pois: Que motivos terão contribuído para que o legado do artista da rainha D. Leonor de Lencastre tenha inspirado e continue a inspirar tanto interesse, 500 anos após o início da sua carreira e 450 depois de, pela primeira vez, ter vindo a lume o conjunto das suas obras?

Nesta tentativa de explicação, não deve deixar de se ter em conta, desde logo, a extensão e variedade do corpus em apreço. As quase cinquenta peças recobrem os grandes géneros do teatro medieval europeu, constituindo, em si mesmas, um raríssimo valor patrimonial, que abrange as línguas portuguesa e castelhana (qualquer delas captada numa impressionante multiplicidade de níveis e registos) e as formas artísticas moldadas a partir de uma tradição de base peninsular e extrapeninsular, que incluía o lirismo, a narrativa e várias formas dialogadas. Por detrás dessas formas mais reconhecíveis, é inclusivamente possível pressentir um vasto conjunto de práticas não discursivas próprias da convivialidade palaciana, de base lúdica e cerimonial. 
Neste mesmo sentido, deve mencionar-se outra condicionante que, embora sendo de natureza cívica e política, se revela igualmente poderosa. Refiro-me ao próprio estatuto de dramaturgo quinhentista, que, neste caso, se vê reforçado com a aura de testemunha viva do tempo mítico que, em Portugal, continua a ser o século XVI. À direita mas também à esquerda, o quinhentismo continua a ser visto como época dourada, ao longo da qual o país conseguiu fazer sobrepor grandezas a misérias.

Lembre-se, por fim, a absoluta excecionalidade do Livro das Obras no panorama da criação teatral portuguesa, em termos de qualidade (e até de quantidade), considerando não apenas o século de Quinhentos mas todos os que até hoje se lhe seguiram. Em função dessa singularidade, pode afirmar-se que, para além dos seus méritos próprios, a obra de Gil Vicente vale também pelo seu desacompanhamento. O mesmo é dizer que, contrastando com os silêncios que a precedem e se lhe seguem na história do teatro português, a obra vicentina conjuga uma relativa raridade com a incidência num tempo muito particular.

Um dos motivos que mais vezes se aponta para explicar a importância de um determinado autor é a duração e a intensidade do seu magistério.

Em relação a Gil Vicente, porém, esse fator não pode ser invocado da mesma forma, uma vez que, como é sabido, o magistério do dramaturgo é de natureza esparsa e diferida, não podendo nunca comparar-se aos que exerceram e continuam a exercer qualquer um dos dois autores que com ele competem em termos de notoriedade: Camões e Fernando Pessoa.

À primeira vista, são estas as razões principais que fazem de Gil Vicente um autor decisivo da literatura e da cultura portuguesas, ao mesmo tempo que lhe garantem um lugar muito especial no imaginário coletivo dos portugueses.

E são também estas as razões que explicam o grande caudal bibliográfico que tem inspirado. Nos vinte anos que medeiam entre 1975 e 1995, puderam recensear-se 620 contributos, contando edições, traduções e estudos gerais ou localizados ${ }^{1}$. A este número há ainda que somar os trabalhos publicados

1 Esta contabilidade exata figura na Bibliografia vicentina que tem vindo a ser publicada por Constantine C. Stathatos e que conta já três volumes. 
desde 95 para cá2: tomando por base apenas o ritmo médio das duas últimas décadas, chegamos à apreciável média de 35 trabalhos por ano.

Tanta quantidade e tanta diversidade requerem, porém, um esforço de esquematização. É isso que se procurará agora levar a cabo: delinear uma visão sistemática dos estudos vicentinos tal como eles se apresentam hoje, sobretudo na universidade. Tentarei depois captar algumas das tendências que se desenham num futuro próximo, mencionando algumas das tarefas mais importantes que permanecem por cumprir.

\section{2.}

Como é sabido, a perceção moderna da obra de Gil Vicente deve-se, em Portugal, ao Romantismo. Há boas razões para acreditar que tenha sido Almeida Garrett a recomendar a Barreto Feio e Gomes Monteiro (dois judeus de origem portuguesa, radicados em Hamburgo) a reimpressão da Copilaçam, o que estes fizeram a partir de um exemplar da $1 .^{a}$ edição que se encontrava na Biblioteca da Universidade de Göttingen. E foi a partir deste acontecimento (1834) que Gil Vicente se tornou conhecido e estudado por uma plêiade de filólogos dos finais do século passado e princípios deste. Foram primeiro as investigações factualistas de Brito Rebelo, Teófilo Braga, Óscar de Pratt e, sobretudo, de Braamcamp Freire a definirem - com maior ou menor acerto - o quadro em que se moveu o dramaturgo, empenhando-se em fixar datas e coordenadas histórico-culturais. É ainda essa a fonte de alguns dos lugares-comuns que, derivando para os programas escolares, continuam a servir de referência ao entendimento do autor: artista de corte, satirista anticlerical, autor de transição entre a Idade Média e o Renascimento, artista de extração popular, defensor da expansão cruzadística, etc. Num outro plano, merecem destaque os esforços de D. Carolina Michaëlis de Vasconcelos que, apesar de não ter podido levar a cabo a edição crítica que chegou a assumir como tarefa prioritária do seu labor

2 Em finais de 2001, Stathatos publicou a mais recente atualização da sua Bibliografia, incidindo, desta vez, sobre os seis anos que medeiam entre 1995 e 2000. Nela se dá conta de 64 trabalhos de natureza crítica (livros, monografias, teses e panfletos) e de 32 artigos integrados em revistas. 
científico, deixou nas suas Notas Vicentinas do que de melhor se produziu em Portugal em termos de identificação contextual (Notas I e II) e de exame filológico (Nota III) no sentido mais útil e honesto da expressão ${ }^{3}$.

Apesar dos esforços de contextualização que foram sendo feitos, a mitologia romântica (que, pelo menos em Portugal, conviveu pacificamente com o positivismo filológico) depressa se apropriou da figura de Gil Vicente, transformando-o numa encarnação da vox populi, espécie de génio sem suporte nem explicação racionais, uma vez que, como se sabe, na teogonia romântica os génios distinguem-se exatamente por não necessitarem de um suporte histórico.

Tão forte viria a revelar-se esse processo de lendarização (abrangendo ainda outras figuras literárias do século xvi como Bernardim e Camões) que o fenómeno acabou por exceder, em muito, os limites cronológicos do próprio Romantismo. Nem os trabalhos de António José Saraiva, que, um tanto incompreendidamente, em finais de 30, colocam a obra vicentina na senda da vasta e rica tradição situável no centro e norte da Europa, entre finais do século XV e meados do século XVI, conseguiram obstar ao velho preconceito romântico de que Gil Vicente representa uma espécie de meteoro desacompanhado no firmamento idiomático e cultural da Península. Retomando uma pista que remonta pelo menos a Aragão Morato $^{4}$ e a que o próprio Teófilo Braga dera expressão mais consistente ${ }^{5}$, o então jovem professor de Lisboa procurou sobretudo demonstrar que o teatro de Gil Vicente deve ser visto como uma espécie de síntese epigonal de todo o teatro da Idade Média, tal como ele se desenvolveu na região meridional da Europa (em certas zonas da Península Ibérica, em Itália e, sobretudo, em França).

Ao contrário de Saraiva, que procurou situar-se no plano da interpretação estética, críticos como Paulo Quintela, Costa Pimpão, A. E. Beau, I. S. Révah, Eugenio Asensio ou Mário Martins optaram por fazer incidir as suas averiguações

3 Neste mesmo volume, José Camões e João Nuno Sales Machado procedem a um reexame de algumas dessas coordenadas.

4 Cf. F. M. Trigoso de Aragão Morato, "Memoria sobre o theatro portuguez", in Memorias da Academia das Sciencias de Lisboa, vol. v, parte II, pp. 46-58.

5 Cf. História do Teatro Portuguez. Vida de Gil Vicente e Sua Eschola, Porto, Imprensa Editora, 1870, pp. 388-391. 
sobre aspetos temáticos, privilegiando o problema das fontes. Independentemente da importância atribuída a fatores estéticos e culturais, a verdade é que estes investigadores não se limitaram a apontar alguns dos antecedentes diretos e indiretos do teatro de Gil Vicente. Foi também graças ao seu labor que se foi construindo a identificação genealógica do Livro das Obras, com tudo o que isso envolve no domínio da própria clarificação do sentido que se desprende dos autos. Está longe de ser uma questão irrelevante, por exemplo, determinar a dívida das Barcas para com a tradição das artes moriendi ou das danças da morte; como está longe de ser ocioso averiguar até que ponto uma peça como Triunfo do Inverno ou do Verão acompanha a sugestão literária e iconográfica dos triomphi de origem italiana.

Grande parte do labor de nomes cimeiros do vicentismo como Paul Teyssier, Luciana Stegagno-Picchio, Stephen Reckert, Cleonice Berardinelli, Thomas R. Hart ou o próprio António José Saraiva, que chegou a reformular o seu vicentismo em diversas direções, pode ainda ser lido como uma tentativa de desromantizar o dramaturgo português. Mas sem grande sucesso, nesse plano. A avaliar pelo que continua a ver-se escrito, conclui-se que não se pode ainda prescindir totalmente desse logótipo, até porque — reconheçamo-lo - ele se enquadra exemplarmente no nosso esquema mítico de

pensar e de sentir. À semelhança do que sucede com Camões e, num plano diferente, também com Bernardim Ribeiro, Sá de Miranda e António Ferreira, Gil Vicente integra um conjunto canónico bem organizado diretamente reportado ao século xvi e ao que ele evoca de ilusões de grandeza coletiva. Isto significa, na prática, que os historiadores da literatura portuguesa não resistiram à tentação de apreciar Gil Vicente no quadro de uma lógica constelativa, reservando ao dramaturgo um papel central na incorporação da realidade. A outros, que não a Gil Vicente, teria cabido a missão de subverter essa mesma realidade, em registo de ficção ou de utopia.

Olhando para o índice de nomes com que se encerra o já citado volume da Bibliografia de Stathatos e destacando de entre eles os que são 
responsáveis pelos contributos de maior relevo, verifica-se, em primeiro lugar, que o inventário dos vicentistas incontornáveis vai aumentando a bom ritmo e, ao lado dos consagrados nos anos 60 e 70, outros nomes foram ganhando foros incontornáveis: Maria Idalina Resina Rodrigues, João Nuno Alçada, María Luisa Tobar, Armando López Castro, Manuel Calderón, María José Palla, Anne-Marie Quint, Olinda Kleiman, Stanislav Zimic, Fábio Moniz e o próprio Constantine C. Stathatos.

Como não poderia deixar de ser, por entre os títulos mais recentes, detetam-se algumas duplicações de perspetiva e de resultados obtidos; mas também se veem alguns movimentos de renovação numa área que, aliás, durante muito anos, permaneceu sequestrada pela história literária, quase imune, portanto, aos ventos novos que vieram fecundar as metodologias dos estudos teatrais e histórico-sociológicos.

Continua a predominar a tendência para o estudo isolado de um só auto, correspondendo, muitas vezes, a incursões esporádicas de estudiosos não reincidentes; mas é necessário reconhecer que são já em número significativo os estudos que abrangem o Livro das Obras ou, pelo menos, alguns conjuntos de peças, delimitados em moldes temáticos ou genológicos: a farsa, a comédia, a representação da Mulher, do Natal, do Amor, a projeção cénico-teatral dos textos, etc. Ainda numa linha estruturante e global, a lírica vicentina, cuja importância foi desde sempre intuída, vem merecendo uma atenção crescente, dando lugar a edições antológicas, que não deixam de surpreender quem tem dos autos um conhecimento mais rarefeito ou dando origem a estudos de sólida fundamentação que religam Gil Vicente à grande tradição da lírica ibérica de Quatrocentos, nas formas e nos temas. Por fim, tem-se procedido, cada vez mais, à busca de um significado global da lírica enquanto correlato dialético de outras formas de expressão (V. Reckert e, na sua senda, Calderón e López Castro). Mal conhecido e pouco valorizado durante décadas, o lirismo peninsular de Quatrocentos tem vindo, nos últimos anos, a ser objeto de interesse crescente, em termos de edição e exegese crítica. Uma das causas dessa prolongada obscuridade prende-se, aliás, com a ideia, também ela preconceituosa, de que se trata de uma realidade epigonal e não precursora. Ao invés de Bernardim, Miranda e Camões, poetas que fecundaram sucessivas gerações de sucessores, nomes 
como Garcia de Resende, Álvaro de Brito ou Anrique da Mota passam por ser poetas de época, no que a designação envolve de mais limitativo. Ainda assim, a escrita desses poetas não pode ser objeto de um só ângulo de avaliação. Trata-se, antes de mais, de uma escrita performativa, de forte influência retórica e de base diccional, e foi justamente essa vertente que a tornou vizinha do primeiro teatro peninsular. Não esqueçamos que Juan del Encina e Lucas Fernández foram, também, indistintamente poetas e dramaturgos. E foi-o ainda Gil Vicente, em proporções muito semelhantes (embora em níveis diferentes de maturação).

\section{4.}

Perante sinais tão positivos, pode pensar-se que os estudos vicentinos se encontram a caminho do lugar que lhes compete, por direito próprio, no âmbito da história literária e cultural (portuguesa e peninsular, pelo menos). Mas convém não embarcar em contentamentos de suficiência, uma vez que as lacunas são ainda numerosas Sem pretensões de exaustividade, anotemos apenas cinco: as edições; a língua; as matrizes estéticas; as coordenadas contextuais e os sentidos.

\section{1 .}

Um dos sinais que melhor reflete o grau de desenvolvimento de uma determinada área dos estudos literários é, como se sabe, o grau de fiabilidade que merecem os textos disponíveis. E, para o caso de Gil Vicente, apesar de progressos significativos consumados nos últimos anos, a situação não se pode ainda considerar satisfatória. Continuam tímidos os passos dados para se chegar a uma edição crítica, desde logo. Em 1965 (ano em que se comemorou o $4 .^{\circ}$ centenário do nascimento do autor) chegou a ser constituída, para o efeito, uma ampla comissão nacional. Passadas mais de três décadas, os dedos de uma só mão chegam para contar as edições que podem reclamar-se de críticas (e creio que, daquelas que existem, nenhuma 
veio a beneficiar desse impulso comemoracionista). Em contrapartida, cresceu bastante o número de edições didáticas, embora de um número de autos cada vez mais restrito, acompanhando, por razões de mercado, a substancial redução do cânone vicentino nos programas de Português dos ensinos básico e secundário. São em suporte escrito e também já em suporte informático, mas repetem, por sistema, os erros de leitura, tão favorecidos, como se sabe, pelas deficiências da própria editio princeps. De resto, mais do que com a fiabilidade dos textos apresentados, os cuidados são postos em estratégias mais ou menos inventivas, tentando apresentar imagens fáceis, divertidas e, sobretudo, anacronizantes. São as consequências normais da presença de Gil Vicente na escola, onde aparece reduzido a meia dúzia de ideias feitas, que oscilam sobretudo em função das conjunturas cívico-políticas e em resultado do capricho (muitas vezes insondável) dos autores de programas e manuais ${ }^{6}$.

Mais inaceitável do que a escassez de edições críticas é, ainda, a penúria de edições globais fidedignas. No mercado português encontram-se hoje a edição da Lello \& Irmão (que se limita a reproduzir, em aparato, a que Mendes dos Remédios preparou em 1907 para a coleção «Subsídios para a História da Literatura Portuguesa»); encontra-se ainda a edição de Costa Pimpão que, apesar da sua melhor qualidade científica, é "artística", o que significa dizer que é ainda mais cara, além de pouco prática, pelas suas invulgares dimensões. A edição dos clássicos Sá da Costa (preparada por Marques Braga, há cerca de sessenta anos) cumpriu razoavelmente a sua missão na escola portuguesa ao longo de trinta anos, mas já só se encontra em alfarrabistas; até a que Maria Leonor Buescu preparou para a Imprensa Nacional, há vinte anos (com normalização de texto), e que alimentou o mercado universitário ao longo das duas últimas décadas, se encontra já fora da vista dos potenciais compradores.

Mais recentemente, e ainda sob efeito de uma outra celebração (os 500 anos do Monólogo do Vaqueiro, celebrados em 2002), apareceu uma nova edição das Obras de Gil Vicente, com fixação de texto em dois volumes,

6 Sobre a presença de Gil Vicente na escola, veja-se o estudo assinado neste compêndio por Amélia Correia. 
mais dois, contendo a reprodução em fac-símile da Compilação de 1586 e dos folhetos quinhentistas até hoje identificados e ainda um quinto volume, contendo notas, glossário, bibliografia e vários índices. O empreendimento dirigido por José Camões resultou diretamente da edição de um CD-ROM, publicado apenas um ano antes, e constitui, sem nenhuma dúvida, uma excelente iniciativa, do ponto de vista patrimonial, não só pela lição substancialmente melhorada que agora se propõe do texto vicentino mas também porque proporciona ao leitor curioso (e mesmo ao investigador) materiais de muito difícil acesso, comodamente reunidos e editados.

Isto não significa, porém, que tenha deixado de haver lugar para outro tipo de edições parcelares ou integrais, destinadas a um público ainda mais vasto, com introduções críticas a cada auto ou a cada conjunto de autos, bibliografias seletivas e, sobretudo, as notas explicativas, em pé de página, em quantidade suficiente para tornar os textos verdadeiramente acessíveis. De forma ainda mais clara: nota-se a falta de uma edição que possa corresponder ao modelo dos clássicos Sá da Costa, revisto e atualizado em função dos progressos entretanto alcançados nos estudos vicentinos e em função dos destinatários reais e potenciais do nosso tempo e dos tempos mais próximos. Em si mesma, a falta é muito significativa. O trabalho em causa é moroso e difícil de empreender, requerendo o empenhamento de uma equipa que, para além de especialistas em crítica textual e em história da língua, deveria ainda contar com pessoas familiarizadas com as formas e os sentidos do teatro medieval, em geral, e da obra de Gil Vicente, muito em particular. E logo por aqui se avalia a dificuldade em congregar as vontades, as competências e os meios necessários para levar avante esse cometimento.

Também o panorama das traduções está longe de ser excelente. Para além das Barcas, do Auto da Alma e de Sibila Cassandra (peças muito traduzidas para quase todas as línguas europeias na primeira metade do século xx), tem-se verificado uma natural curiosidade pelos autos que refletem as circunstâncias da Expansão, inspirando um número razoável de versões, nomeadamente em língua inglesa. Menção muito positiva, a este respeito, merecem as traduções francesas coordenadas por Paul Teyssier, que começaram a vir a lume, sob a chancela das Éditions de la Chandeigne, já na 
década de $70^{7}$. Mas se a este excelente exemplo quiséssemos contrapor um fenómeno de sinal contrário, não seria difícil: bastaria aludir às edições do teatro exclusivamente castelhano de Gil Vicente (feitas por espanhóis e publicadas em Espanha) e a outras feitas em Portugal, sistematicamente expurgadas dos autos em castelhano ou até dos textos bilingues.

Enquanto este estado de coisas subsistir, é bem provável que Gil Vicente continue ausente das histórias do teatro europeu. Em Itália, em França ou nos países anglo-saxónicos, o dramaturgo português constitui ainda uma escandalosa ausência, sendo objeto, quanto muito, de referências fugazes e algumas vezes deturpadas. E isto apesar de, em teoria, se ter tornado impossível a reconstituição dos grandes géneros do teatro medieval, à revelia do seu legado. Não se pode aceitar, por exemplo, a identificação acrítica de Gil Vicente com Encina e Fernández, sistematicamente agrupados (os três) nas histórias do teatro espanhol, no rol dos "primitivos» ou dos "precursores".

As insuficiências de base verificadas nestes dois planos não podem obviamente deixar de condicionar a produção crítica, uma vez que daí resultam dificuldades naturais no acesso aos textos. Deste modo, impõe-se a necessidade de conjugar esforços para

a) Elaborar uma edição integral de Gil Vicente, com notas de caráter filológico e histórico-cultural, de modo a tornar acessível, na sua globalidade, um corpus único na história da cultura portuguesa. Para tanto, torna-se necessário estabelecer critérios de anotação, que deverão ir desde o esclarecimento vocabular localizado e cotextual até ao comentário estético e ideológico ${ }^{8}$.

7 A iniciativa contou, no início, com a coordenação muito ativa de Paul Teyssier e prosseguiu sob a égide de alguns dos seus discípulos na universidade francesa, de que é justo destacar Anne Marie Quint e Olinda Kleiman. Para uma resenha do projeto e dos critérios em que assenta, veja-se a entrevista de Anne Marie Quint, conduzida por Christine Zurbach, in Adágio, 34-35 (setembro de 2002/janeiro de 2003), pp. 137-141.

8 De entre os muitos exemplos que se poderiam destacar no panorama editorial espanhol (ficando-nos, assim, por um espaço bem próximo), cinjo-me apenas a uma edição da Celestina, preparada por uma equipa que integra nomes como Francisco J. Lobera, Gillermo Será, Paloma Díaz-Mas, Carlos Mota, Migo Ruiz Arzálluz e Francisco Rico, com vários estudos, aparato crítico, notas, bibliografias e índices que se estendem por quase um milhar de 
b) Depois - ou paralelamente? — deve levar-se por diante a tão almejada edição crítica, ainda mais trabalhosa, mas, ainda assim, perfeitamente exequível (sobretudo, em face dos progressos assinaláveis que a edição de José Camões consagrou a este nível) e, sobretudo, amplamente justificada em face dos benefícios que promete.

\section{2.}

$\mathrm{Na}$ posse destes dois elementos de trabalho, seria, sem dúvida, muito mais fácil levar por diante tarefas de outra índole, enfrentando problemas que, desde há muito, se encontram suspensos. Era necessário voltar à questão da língua, em primeiro lugar. Sobre este assunto, Paul Teyssier disse praticamente a primeira e a última palavra. Mas disse-a em 1959. Na mesma perspetiva ou adotando outros enfoques, impõe-se retomar o estudo da langue vicentina, em correlação com os vários registos do discurso literário e não-literário da mesma época, nos domínios idiomáticos do castelhano e do português, através de cruzamentos que os recursos informáticos vieram entretanto facilitar enormemente. Penso sobretudo na questão do léxico, onde, depois de Teyssier, os caminhos se encontram bem desbravados; e tenho muito concretamente em vista os trabalhos que se desenvolveram já a propósito de obras em castelhano contemporâneas de Gil Vicente, como é o caso da Celestina. Mas seria igualmente muito bem recebido um inventário dos tópicos enunciativos ou da prodigiosa gama de situações de diálogo dramático registadas ao longo dos autos?.

Para além de outras vantagens, o estudo da morfologia do diálogo permitiria estabelecer, de forma mais rigorosa, o complexo de matrizes a que se reporta a obra vicentina e surpreender a grande versatilidade estética que a assinala, contribuindo, ao mesmo tempo, para uma demarcação necessária

páginas. São muito variados os motivos para pensar que um conjunto como as Barcas, por exemplo, há muito que requer uma atenção deste tipo.

9 A este propósito, Telmo Verdelho acaba de publicar uma utilíssima Concordância da Obra Toda de Luís de Camões, cujo modelo pode ser transposto para outros autores e, desde logo, para Gil Vicente (Coimbra, Centro Interuniversitário de Estudos Camonianos, 2012). 
entre os muitos tipos de diálogo cultivados ao longo da modernidade (séculos XV a XVII).

\section{3.}

Julgo também necessário reexaminar a questão das matrizes da arte vicentina. Concebido durante muito tempo como uma ave insólita nos céus rarefeitos da dramaturgia portuguesa, Gil Vicente permanece ainda escassamente integrado na tradição peninsular e europeia, em geral, tanto em termos de ascendência como em termos de projeção. Questões como a dos géneros teatrais ou a dos próprios esquemas de encenação muito terão a ganhar com este trabalho de inserção que liberte a obra vicentina das fronteiras políticas e até idiomáticas a que tem estado confinada. Neste plano particular, é claro que os estudos vicentinos beneficiam com o grande incremento de publicações de textos dramatúrgicos, inéditos ou reajustados em bases filológicas mais seguras, que se vêm fazendo no espaço francês e espanhol, e bem assim dos estudos acerca do teatro tardomedieval (nomeadamente o de expressão francesa $)^{10}$; como podem beneficiar significativamente com os novos quadros de leitura abertos pela semiologia do texto dramático, concebido, não já como objeto linear e passivo, mas como objeto poligonal e transversalmente codificado. Num caso como no outro, consolida-se a ideia de que a criação vicentina se inscreve em coordenadas histórico-culturais e estéticas que não têm que ver apenas com a realidade portuguesa.

\section{4 .}

Outro aspeto que carece de atenção prende-se com as coordenadas contextuais que balizam a produção e a receção dos textos vicentinos. Superados

10 Cumpre designadamente assinalar os doze volumes de farsas, que vieram a lume, muitos deles pela primeira vez, através da mão competente e devotada de André Tissier (Paris, Droz, 1986-2000). Empreendimento semelhante foi já iniciado para as moralidades, numa edição dirigida por Estelle Doudet, cujo primeiro volume veio já a público nos Classiques Garnier (2012). 
há muito os limites e os excessos do contextualismo determinista que marcaram os estudos literários até à primeira metade deste século e preservada a especificidade do fenómeno estético, estão abertos os caminhos para que se aproveite mais e melhor o contributo das disciplinas historiográficas (história da arte, das mentalidades e dos planos institucional e político). Paralelamente ao enraizamento estético, torna-se indispensável esclarecer melhor os parâmetros da convivialidade cortesã em Portugal, no primeiro terço do século XVI, ajustando a leitura dos autos ao que de novo se tem vindo a publicar sobre estas matérias. Nos anos mais recentes, têm surgido contributos importantes, nomeadamente no que se refere à figura da rainha D. Leonor de Lencastre e às linhas de espiritualidade que lhe são próximas e cuja repercussão no teatro vicentino merece atenção demorada. A este propósito, dispomos hoje de dois sólidos e desenvolvidos trabalho de investigação consagrados a $\mathrm{D}$. Leonor, aos seus desígnios e aos efeitos da sua ação. Refiro-me, em primeiro lugar, à investigação levada a cabo por Ivo Carneiro de Sousa. Nesse trabalho se aclaram com nova e abundante documentação e com sentido crítico muito prudente algumas das suposições que até aqui circulavam sem bases suficientes: a propósito da misericórdia e de tudo o que ela envolve enquanto princípio fundamentador da ação leonorina, das principais orientações da sua religiosidade, das condições em que se constituiu e evoluiu a casa e a corte da esposa de D. João II, etc. De vez em quando, Carneiro de Sousa faz menção do teatro de Gil Vicente, tentando nomeadamente vinculá-lo ao quadro edificante que resulta destas circunstâncias. Mas são insuficientes os nexos estabelecidos e, por vezes, ainda frágeis as conclusões extraídas ${ }^{11}$. Doravante, porém, os vicentistas não poderão prescindir deste valiosíssimo acervo de informação no aclaramento dos parâmetros contextuais em que se moveu o dramaturgo ${ }^{12}$.

11 Refiro, por exemplo, a leitura do Auto da Alma no pressuposto de que a peça se integra no quadro mais vasto do teatro de misericórdia. Partindo da informação didascálica (mais do que duvidosa, aliás) de que a peça foi representada em 1508, Carneiro de Sousa situa-a concretamente no termo de uma procissão de Misericórdia, realizada em quinta-feira de endoenças (cf. op. cit., pp. 409 e segs.).

12 Num dos anexos, o autor estabelece novas aproximações à casa, capela e aos círculos sociais e religiosos de D. Leonor, identificando 178 individualidades de algum modo relacionadas com a rainha. No que toca a Gil Vicente, porém, não regista novidades, subscrevendo, na 
Refiro-me, por fim, à ainda mais recente monografia dedicada à mesma figura por Isabel Guimarães de Sá, mais centrada nas vicissitudes políticas e humanas que lhe pautaram a existência mas não esquecendo o ambiente devocional que a envolveu e que podem também ter tido ecos na dramaturgia vicentina ${ }^{13}$.

De forma mais lata, também é preciso reconhecer que se tem progredido no conhecimento do século XVI, em geral, em termos sociopolíticos e mentais, abrindo caminhos para a aferição da importância que, em Gil Vicente, detém a tradição popular, seja ela vista como um depósito cultural que os palácios não excluíam, seja ela entendida como uma opção estética consequente. De facto, desde Carolina M. de Vasconcelos e Teófilo Braga que se intuiu e valorizou a importância do substrato folclórico no teatro de Gil Vicente. Colocada apenas nestes termos, porém (raramente se tem ido mais longe), a questão é vaga, necessitando muito de aprofundamento e de realinhamento de perspetiva, à luz do muito que entretanto se avançou nestes domínios ${ }^{14}$.

A persecução deste rumo não deixa de implicar riscos importantes. Durante muitos anos, o teatro vicentino foi assumido como ponto de partida para aceder à compreensão do século XVI, funcionando, nessa medida, como fonte quase ilimitada da maioria dos historiadores. Parece também chegado o momento de os historiadores enriquecerem os estudos vicentinos com conhecimentos obtidos em fontes diferentes. Só assim será possível discriminar aquilo que é manifestamente testemunhal, aferir o grau da transformação estética que a partir daí se operou e dirimir, enfim, com senso hermenêutico, velhas questões dos estudos vicentinos como sejam o realismo, a sátira ou o cómico, indexado às figuras e às situações da época.

É tempo, também, de os estudos vicentinos beneficiarem da reconversão de perspetivas que algumas correntes mais recentes trouxeram para os estudos literários e para os estudos teatrais. Refiro-me, em primeiro lugar,

prática, as interpretações de Braamcamp Freire, nomeadamente no que toca à tese da identidade entre o dramaturgo e o ourives (cf. pp. 856-857).

13 Cf. De Princesa a Rainha Velha. Leonor de Lencastre, Lisboa, Círculo de Leitores, 2011.

14 Para além do seu mérito intrínseco, o estudo de Pedro Ferré sobre cultura popular que figura neste volume abre caminhos muito promissores. 
ao New Historicism ou Poética Cultural, corrente que se afirmou nas universidades anglo-saxónicas ao longo dos anos 80 e 90, tendo justamente como centro a dramaturgia do Renascimento, em geral, e a obra de William Shakespeare, em particular.

No caso vertente, tratar-se-ia, antes de tudo, de assumir que a obra de Gil Vicente corresponde à textualização de uma determinada realidade (irrecuperável em si mesma, como todas as realidades do passado), havendo todo o interesse em proceder a estudos integrativos de alcance mais vasto, tendo em consideração outros processos textuais, literários e não literários. Aproximar os autos vicentinos de textos teológicos, cronísticos, jurídicos, tratadísticos ou promover a sua comparação com outros tipos de discurso artístico produzidos a partir dos diferentes focos de poder não seria, em alguns casos, coisa inédita. Mas seria realmente novo transformar esse trabalho em projeto de investigação sistemático, perseguindo, desta vez, não a utopia da leitura totalizante e definitiva (era esse o projeto último do velho historicismo filológico) mas o aclaramento progressivo e sempre condicionado dos circuitos de energia cultural que envolvem a cultura da época de Gil Vicente.

$\mathrm{Na}$ medida em que pressupõe uma aproximação a zonas mais obscuras ou menos «centrais», uma orientação deste tipo poderia também contribuir para instituir novos focos de interesse, em ordem a uma outra visão dos textos e dos contextos em apreço, que fosse, ao mesmo tempo, mais culta do ponto de vista teórico e menos preconceituosa do ponto de vista ideológico.

No âmbito das novas orientações, refiro, por fim, o pós-colonialismo que, no caso de Gil Vicente como em outros exemplos da literatura do século XVI, detém um assinalável potencial de aplicação ${ }^{15}$. Há sobretudo que ter em conta, a este propósito, que as primeiras leituras de Gil Vicente foram cunhadas sob a égide de fortes preconceitos coloniais e que a sua

15 Como termo de comparação, evoque-se uma tentativa de ler Camões sob a égide do pós-colonialismo, corporizada em número monográfico de uma revista universitária americana consagrada a assuntos portugueses: Portuguese Literary and Cultural Studies, 9 (2002), subordinado ao título "Post-Imperial Camões». Embora em alguns estudos prepondere largamente a tónica reativa e iconoclasta, é indesmentível que a reconversão de perspetiva se traduz, em alguns casos, em evidentes aquisições de conhecimento e, sobretudo, na relativização de um saber ideologicamente marcado, que se vinha repetindo sem o necessário exame crítico. 
repercussão no sistema de ensino foi particularmente marcante ao longo de muitas décadas. Uma revisão pós-colonial da obra vicentina passaria, assim, em primeiro lugar, pela desconstrução de preconceitos de caráter político e ideológico que vêm assinalando a investigação e o consumo escolar do autor; o seu maior ganho, porém, residiria numa maior valorização das componentes estéticas em presença.

4.5 .

Efetuadas estas operações prévias, será altura de aprofundar os sentidos da obra vicentina, concebida não apenas como aglomerado de peças mas como macrotexto, ou seja, como totalidade orgânica apoiada em linhas de coerência temática e ideológica. Existe verdadeiramente um ideário vicentino? Como se projeta ele através do jogo teatral? Quais as componentes estéticas que lhe dão corpo? Que tipos de correlação se estabelecem entre elas? Levando estas questões ainda mais fundo, poderemos perguntar: participa ou não Gil Vicente do movimento identitário que atravessa a cultura portuguesa do século XVI? Se respondermos afirmativamente a esta pergunta, teremos em seguida que enfrentar outro desafio: aferir a densidade dessa participação, usualmente confinada aos círculos e correntes do Humanismo.

Estas perguntas poderão parecer demasiado gerais. E, no entanto, se não erro, são elas que hoje melhor ilustram as expectativas atuais dos devotos vicentistas. Daqueles que estudam os textos e daqueles que, pura e simplesmente, mantêm com eles uma relação de curiosidade fruitiva e indagante.

Independentemente das respostas que se possam vir a encontrar para estas questões, talvez se possa reconhecer, desde já, a utilidade da sua simples formulação. Quanto mais não seja, porque ela se revela suscetível de abalar algumas verdades, que vêm circulando desde há muito, com trânsito demasiado fácil.

Como era inevitável, o lugar central que Gil Vicente ocupa no cânone português contribuiu para uma cristalização excessiva do conhecimento que sobre ele tem sido divulgado. A esse respeito, aliás, parece bem sintomático que o autor das Barcas não tenha sido alvo de atenção por parte de 
alguns grandes portugueses, que tanto contribuíram para legitimar novas aproximações a outros autores do cânone (nem Sérgio, nem Lourenço ${ }^{16}$, nem Aguiar e Silva, por exemplo, lhe tocaram de forma consistente).

Costuma dizer-se, aliás, que essa é a "defesa» dos clássicos e é também, sem dúvida, o segredo do seu sucesso num determinado modelo de escola. Resta saber, porém, se essa situação se compadece com a escola que todos afirmamos querer construir: ativa e não dormente, criativa, transformativa e não redutoramente patrimonialista. Como, aliás, é inaceitável que esta visão pobre possa ser transposta para círculos de maior exigência intelectual, como a própria universidade, afinal também visivelmente constrangida quando se trata de lidar com nomes decisivos do nosso cânone literário e cultural.

16 Há poucos anos, foi, no entanto, publicado um texto inédito de Eduardo Lourenço sobre Gil Vicente. Trata-se, claramente, de uma reação ao vicentismo que nos anos 50 era desenvolvido por António José Saraiva, numa linha marxizante (Cf. «O gibão de mestre Gil»). 